\title{
REPRESENTASI MONO NO AWARE YANG TERCERMIN DALAM FILM "GOEMON" KARYA KAZUAKI KIRIYA
}

\author{
I.P.D.R. Suciptha ${ }^{1}$, G.S. Hermawan ${ }^{2}$, N.N. Suartini ${ }^{3}$ \\ ${ }^{123}$ Jurusan Pendidikan Bahasa Jepang, Universitas Pendidikan Ganesha, Singaraja \\ e-mail: dodyramasuciptha@gmail.com, satya.hermawan@undiksha.ac.id, nnsuartini@undiksha.ac.id
}

\begin{abstract}
ABSTRAK
Penelitian ini bertujuan untuk mendeskripsikan rasa keindahan Jepang yang disebut dengan Mono No Aware yang selalu diwarnai dengan kesedihan dan kepiluan. Untuk memudahkan meganalisis Mono No Aware penelitian ini menggunakan film Goemon menceritakan tentang pertempuran Sekigahara dengan kepahlawanan Goemon yang legendaris, yaitu dengan mencuri barang dari orang kaya dan memberikannya kepada orang miskin yang menggambarkan kesengsaraan pada masa tersebut. Penelitian ini bersifat kualitatif karena penjelasan kata bersifat deskriptif. Analisis data dilakukan dengan menggunkan teori Mise En Scene, teori ini meliputi beberapa aspek yaitu, setting, akting, blocking, make-up dan kostum, ruang dan lighting. Hasil penelitian ini menunjukan bahwa dalam film Goemon mendeskripsikan kesedihan dan kepiluan terlihat pada setting, akting, lighting, make-up dan kostum pada setiap scene yang di analisis.
\end{abstract}

Kata Kunci : Film, Mono No Aware, Mise En Scene

\section{要旨}

本研究の目的は、映画「ゴエモン」を分析した。この映画は、小さなコミュニティを守る忍の闘 いの物語である。この映画は悟空時代に語られる、関ヶ原戦におけるごえもんの英雄、金持ちからの 商品の盗難と貧しい人々との共有は悲惨さを表している。映画「ごえもん」に「物の哀れ」の概念を 見つけるため、「物の哀れ」の定義と映画理論を使った。そして、映画にある台詞とシーンを分析の 対象とした。単語分析は記述的でいるために、この本研究は定性的です。データ分析は、三セエンシ ーン理論を使用して実行されました。この理論には、設定、演技、ブロッキング、化粧とコスチュー ム、ルームそして点灯いつかの側面が含まれます。この研究の悔過は、映画のなかでゴエモンが分析 されたかくシーンの設定、演技、ブロッキング、化粧とコスチューム、ルームそして点灯衣装に見ら れるかなしみとかなしみを説明していることをしめしていまた。

キーワード：映画、物の哀れ、三セエンシーン

\section{Pendahuluan}

Mono no Aware (物の哀れ) ini dapat diartikan sebagai ekspresi perasaan tergugah yang terdalam terhadap lingkungan alam sekitar, maupun perasaan tergugah yang menyentuh dalam interaksi antar sesama. Ekspresi perasaan ini bisa muncul sebagai kekaguman, kesedihan, keterharuan dan sejenisnya. Salah satu ekspresi Mono no Aware (物の哀れ) yang dominan yaitu terdapat pada karya sastra Genji Monogatari, Heike Monogatari dan film Jepang seperti Goemon dan Hotaru no Haka yang menggambarkan pandangan ketidakkekalan atau mujokan. Perebutan kekuasaan yang diceritakan pada film Goemon dan kejatuhan klan Taira yang berkuasa adalah salah satu contoh Mono no Aware (物の哀れ) yang memberi makna bahwa kekuasaan tidak ada yang abadi. Ungkapan-ungkapan Mono no Aware (物の哀れ) ini juga muncul dalam karya seni di era sekarang ini, seperti yang terdapat dalam lirik lagu yang berjudul kokoro no tomo. Dengan demikian, Mono no aware (物の哀れ) bisa dikatakan sebagai bagian dari kebudayaan khas Jepang.

Pada abad ke 18, muncul seorang ilmuan bernama Motoori Norinaga (17301801). Norinaga adalah salah seorang pengamat sastra yang berfokus pada studi 
tentang Genji Monogatari dimana kata Aware sendiri sudah digunakan pada saat itu. Kata Aware juga dikenal dengan istilah ahare, yang digunakan sebagai kata ekspresi untuk mengungkapkan gagasan hal yang bersifat senang dan sedih secara bersamaan (Aso,dkk, 1974:32). Lambat laun sejak zaman Norinaga, kata Aware lebih diidentikkan dengan sesuatu yang bersifat sedih dan penyesalan (Kodansha, 1994:1002).

Dalam menonton film menggunakan representasi Mono no Aware (物の哀れ)

ini sangat membantu untuk mevisualkan film tersebut. Penonton yang tidak mengerti bahasa Jepang pun dapat memahami isi cerita film walaupun film yang ditonton tidak memiliki terjemahan (subtitle) ataupun menonton film bisu. Penonton bisa menggunakan Mono no Aware (物の哀れ) untuk menghayati dan mendalami film yang sedang ditonton. Contohnya, disaat menyaksikan film yang bergenre romantis, aksi, komedi, dan lain-lain, penonton bisa merasakan bahkan seperti berada atau ikut serta didalam suasana film tersebut. Sama halnya ketika menonton film yang bergenre sedih tanpa sadar penonton meneteskan airmata karena kesedihan di dalam film tersebut. Itulah cara kerja representasi Mono no Aware (物の哀れ).

Representasi merujuk kepada konstruksi segala bentuk media terutama media masa terhadap segala aspek realita atau kenyataan seperti masyarakat, objek, peristiwa, hingga identitas budaya. Representasi ini bisa berbentuk kata-kata atau tulisan bahkan juga dapat dilihat dalam bentuk gambar bergerak atau film. Representasi tidak hanya melibatkan bagaimana identitas budaya disajikan atau dikonstruksikan di dalam sebuah teks tetapi juga dikonstruksikan di dalam proses produksi dan persepsi oleh masyarakat yang mengkonsumsi nilai budaya yang direpresentasikan (Danesi, 1999). Film merupakan sumber penelitian yang sangat cocok bagi representasi Mono no Aware (物の哀れ) karena film merupakan alat komunikasi yang bersifat audio visual untuk menyampaikan suatu pesan kepada penontonnya. Sifat film inilah yang membuat cocok dengan representasi Mono no Aware (物の哀れ), karena Mono no Aware (物の哀 れ) lebih mudah dipahami dengan visual (pesan dengan media gambar). Seperti pada penelitian-penelitian yang sudah mengangkat film sebagai cerminan dari representasi Mono no Aware (物の哀れ) diantaranya, film anime Hotaru no Haka. Film ini menceritakan tentang perjuangan bertahan hidup dua bersaudara pada masa setelah perang dunia II yang sangat menyedihkan dan menyulitkan untuk dilalui oleh mereka berdua. Penelitian ini menggunakan film yang berjudul Goemon dan menggunakan teori Mise en scene karena mengacu pada segala aspek visual yang muncul pada film, seperti setting, aktor, latar, kostum, pencahayaan dan lain sebagainya. Film Goemon diawali oleh sebuah narasi mengenai Jepang pada tahun 1582. Film Goemon menceritakan tentang kisah perjuangan shinobi yang bernama Ishikawa Goemon yang berjuang membela rakyat kecil. Dalam film ini banyak disajikan Jepang pada era akhir dari periode Sengoku, khususnya periode yang menentukan pertempuran Sekigahara. Dengan kisah kepahlawanan Goemon yang legendaris yaitu mencuri barang-barang dari orang kaya dan memberikannya kepada orang miskin. Untuk memberikan gambaran kesengsaraan pada masa tersebut, ditampilkanlah scene-scene yang memuat Mono no Aware. Sebagai contoh pada scene 22.28 ketika Koheita memberikan makanan kepada ibunya yang sedang sakit. Secara visual digunakan teknik kamera zoom in tepat pada wajah Koheita, dan memberikan efek musik sedih sehingga semakin membuat kejadian tersebut sangat menyedihkan sesuai dengan keadaan Jepang pada pertempuran Sekigahara. Hal inilah yang menunjukan penggunaan Mono no Aware melalui teknik mise en scene. Dalam penelitian ini, peneliti menggunakan film Goemon sebagai cerminan dari representasi mono no aware karena film Goemon adalah film yang menceritakan kejadian pada era pertempuran Sekigahara yang banyak memuat kejadian-kejadian yang sangat menyedihkan sehingga cocok digunakan untuk cerminan representasi Mono no Aware. 


\section{Metode}

Pendekatan dan jenis penelitian yang digunakan dalam penelitian ini adalah penelitian kualitatif dengan teknik deskritif-analisis. Dalam teknik pengumpulan data, penulis menggunakan metode studi pustaka dengan menggunakan buku-buku sebagai referensi serta bahan lainya seperti artikel, jurnal dan publikasi eletronik tentang film dan Mono no Aware. Data dalam penelitian ini adalah data kualitatif. Data disajikan dalam bentuk kata, bukan dalam bentuk angka. Data berbentuk narasi dan uraian penjelasan dari data yang diperoleh dari sumber data (Sarwono, 2006). Sumber data dari penelitian ini diperoleh dari pengumpulan data hasil pengamatan Mono No Aware pada tandatanda visual dari film Goemon. Data yang sudah terkumpul kemudian dikelompokkan berdasarkan data yang akan dianalisis. Kelompok data tersebut akan dianalisis dengan menggunakan teori sesuai dengan pembahasan yang dibahas.

Subjek dalam film ini adalah tokoh-tokoh yang menggambarkan Mono No Aware pada film Goemon. Film Goemon yang di sutradarai oleh Kazuaki Kiriya telah masuk Box office dengan jumlah penonton 14,46 juta orang. Di Amerika film ini merupakan film Asia pertama yang mendapatkan jumlah penonton terbanyak di Amerika. Film ini dipilih karena banyak tokoh-tokohnya yang merepresentasikan Mono no Aware dalam tandatanda visual. Hal tersebut dapat dilihat pada scene ketika ibu dari Koheita sedang menderita karena sakit yang dialaminya dan Koheita memberikan makanan kepada ibunya, disini sangat terlihat raut wajah sedih terpancar dari sang anak yaitu Koheita. Tidak berselang lama penyakit yang diderita oleh ibunya pun kumat. Koheita segera bergegas untuk membeli obat dengan berbekal kotak yang didapatkan ketika Goemon memberikan koin emas kepada masyarakat, ketika ingin bergegas membeli obat, tidak disangka pejabat dan para prajurit pun sudah menanti di depan pintunya. Pejabat tersebut menginginkan kotak yang dibawa Koheita, namun karena kotak tersebut sangat dibutuhkan oleh Koheita, dia pun memberi perlawanan. Ketika memberi perlawanan, Koheita hampir terbunuh. Melihat hal tersebut, ibu Koheita yang sedang sakit berusaha menyelamatkan Koheita. Karena menyelamatkan Koheita ibunya pun terbunuh di depan mata Koheita". Scene inilah yang menunjukan Mono no Aware.

Pengumpulan data penelitian ini menggunakan metode pustaka. Data diperoleh dari film "Goemon" dan sumber yang mendukung. Sumber lain yang dimaksud berupa buku, artikel, jurnal, serta laporan penelitian yang terkait dengan objek penelitian, yaitu mengenai representesi Mono no Aware dalam tanda-tanda visual pada film Goemon. Instrumen yang digunakan dalam pengumpulan data yaitu kartu data. Kartu data berfungsi untuk mengelompokan data pada film Goemon yang menunjukan Mono no Aware dalam tanda-tanda visual. Kartu data adalah sebagai berikut.

Tabel 1.1 Kartu Data

\begin{tabular}{|r|c|c|c|}
\hline Durasi & Visual & Seting & Sisi Mono No Aware \\
\hline & & & \\
\hline & & & \\
\hline
\end{tabular}

Setelah kartu data dibuat, akan ditindaklanjuti dengan pemberian penjelasan pada representasi Mono no Aware dalam tanda-tanda visual dalam film Goemon. Penjelasan tersebut akan dibagi menjadi beberapa durasi dan disertai dengan gambar yang meenunjukan situasi Mono no Aware. Kerangka analisis dapat dilihat di bawah ini.

$\begin{array}{lll}\text { Durasi } & : & \text { Waktu kejadian dalam film } \\ \text { Visual } & \vdots & \text { Gambaran kejadian dalam film } \\ \text { Seting } & \vdots & \text { Bagaimana terjadinya suatu kejadian dalam film } \\ \text { Sisi } & : & \text { Gambaran Mono no Aware dalam film }\end{array}$

Kerangka penelitian tersebut digunakan sebagai acuan untuk menjabarkan tabel kartu data yang telah dijelaskan sebelumnya. Penjabaran seperti tanda-tanda visual pada film yang megandung representasi Mono no Aware pada setiap durasi dan seting untuk mempermudah dalam menganalisis data. Selanjutnya data tersebut dianalisis 
dengan menggunakan teori-teori yang sudah dijabarkan sebelumnya. Dengan berpedoman pada teori-teori dari para ahli dalam menganalisis data, maka kejelasan data tersebut telah valid sesuai dengan kaidah ilmiah.

Teknik pengumpulan data pada penelitian ini dilakukan dalam dua tahap yaitu, teknik dokumen dan observasi. Teknik dokumen yaitu data diperoleh dari dokumendokumen yang berupa catatan formal, artikel, jurnal serta catatan lainya yang berkaitan dengan penelitian ini. Sedangkan teknik observasi yaitu mengadakan pengamatan langsung melalui media yang bersangkutan, dalam hal ini pengamatan langsung dilakukan dengan menonton film Goemon. Kemudian data didapatkan dicatat untuk kemudian dianalisis sesuai dengan analisis yang digunakan. Hal-hal yang dikorpus inilah yang nantinya akan dipaparkan dalam bab pembahasan hasil penelitian. Penelitian ini menggunakan teknik triangulasi untuk mengecek keabsahan data. Triangulasi yang dilakukan yaitu dengan membandingkan hal yang diperoleh dengan teori yang ada, membandingkan hal yang diperoleh dengan penelitian lain yang relevan dan membandingkan hal yang diperoleh dengan penjelasan dari kajian pustaka mengenai hal yang dibahas.

\section{Hasil dan Pembahasan}

Mono no Aware adalah gambaran perasaan tergugah ketika membaca karya sastra sehingga pembaca dapat lebih mudah memahami pentingnya keindahan sebuah karya sastra. Hal ini juga digunakan untuk mengekspresikan emosi yang tajam dan sensitifitas sebuah karya sastra serta perasaan yang dapat membangunkan indera pembaca, seperti deskripsi suara ataupun pemandangan. Mono no Aware dalam Genji Monogatari mengandung arti menaruh iba terhadap kesedihan yang dialami oleh tokoh dalam cerita.

Mono no Aware dalam film Goemon yang mengandung arti menaruh iba terhadap kesedihan yang dialami oleh tokoh-tokoh dalam film. Beberapa kesedihan dalam film Goemon digambarkan secara visual dengan ditandai oleh ekspresi wajah, ekspresi mata, cara pengambilan gambar, efek musik, efek pencahayaan yang mendukung Mono no Aware tersebut.

Untuk menganalisis tanda-tanda Mono no Aware yang tercermin dalam film Goemon, tokoh-tokoh yang terdapat dalam film tersebut perlu untuk dipaparkan terlebih dahulu.

Tabel 1.2 Tokoh-tokoh dalam Film Goemon

\begin{tabular}{|c|l|l|}
\hline No. & Tokoh & \multicolumn{1}{c|}{ Penokohan } \\
\hline 1 & Goemon & $\begin{array}{l}\text { Seorang ninja (shinobi) yang membela rakyat } \\
\text { miskin dan berusaha membuat perdamaian dengan } \\
\text { mencuri uang atau barang-barang berharga milik } \\
\text { bangsawan dan hasil curianya dibagikan kepada } \\
\text { masyarakat kecil atau rakyat yang membutuhkan. }\end{array}$ \\
\hline 2 & $\begin{array}{l}\text { Oda } \\
\text { Nobunaga }\end{array}$ & $\begin{array}{l}\text { Oda Nobunaga adalah seorang daimyo Jepang } \\
\text { atau orang yang memiliki pengaruh besar di suatu } \\
\text { wilayah. Oda Nobunaga dikenal dengan kebijakan } \\
\text { yang kontorvesial seperti penolakan kekuasaan } \\
\text { oleh klan yang sudah mapan, dan pengangkatan } \\
\text { pengikut dari keluarga yang berhasil memenangkan } \\
\text { pertempuran. Selain itu, ia ditakuti akibat } \\
\text { tindakanya yang sering dinali kejam, seperti } \\
\text { perintah seperti perintah membakar semua } \\
\text { penentang yang terkepung di kuil Enryakuji, } \\
\text { sehingga Nobunaga mendapat julukan raja iblis. }\end{array}$ \\
\hline 3 & Saizou & $\begin{array}{l}\text { Saizou adalah teman Goemon pada masa kecil } \\
\text { yang sama-sama berlatih untuk menjadi ninja } \\
\text { (shinobi) yang handal namun Zaizou lebih memilih }\end{array}$ \\
\hline
\end{tabular}


JPBJ, Vol. 7 No. 1, Februari 2021

ISSN: 2613-9618

\begin{tabular}{|c|l|l|}
\hline & & $\begin{array}{l}\text { bekerja dengan daimyo daripada ikut dengan } \\
\text { Goemon menjadi pencuri. }\end{array}$ \\
\hline 4 & $\begin{array}{l}\text { Cha-cha } \\
\text { Sama }\end{array}$ & $\begin{array}{l}\text { Putri kaisar yang merupakan keponakan dari Oda } \\
\text { Nobunaga, mempunyai paras yang cantik dan juga } \\
\text { ingin dijadikan selir oleh Toyotomi Hideyosi. }\end{array}$ \\
\hline 5 & Sasuke & $\begin{array}{l}\text { Pengikut setia Goemon pada masa-masa } \\
\text { kejayaanya saat menjadi pencuri. }\end{array}$ \\
\hline 6 & Koheita & $\begin{array}{l}\text { Anak kecil yang hampir sama karakternya dengan } \\
\text { Goemon. Anak kecil dari rakyat biasa yang bernasib } \\
\text { buruk akibat kekejaman penguasa. }\end{array}$ \\
\hline 8 & $\begin{array}{l}\text { Tokugawa } \\
\text { Leyasu }\end{array}$ & $\begin{array}{l}\text { Angkuh ingin menjadi penguasa. la merupakan } \\
\text { panglima dari Toyotomi }\end{array}$ \\
\hline $\begin{array}{l}\text { Tokugawa Leyasu adalah salah satu dari tiga } \\
\text { pemersatu Jepang pada periode Sengoku. Daimyo } \\
\text { Leyasu berhasil merebut kekuasaan keshogunan } \\
\text { dan mendirikan keshogunan Takugawa, } \\
\text { pemerintahanya dipusatkan di Edo dan sekarang } \\
\text { menjadi Tokyo. }\end{array}$ \\
\hline
\end{tabular}

Dari 8 tokoh diatas, akan dibahas 4 tokoh yang mencerminkan Mono no aware pada film "Goemon". Representasi Mono no Aware oleh 4 tokoh akan dianalisis menggunakan teknik Mise en Scene dengan menyertai setting, ruang, make-up, dan pencahayaan.

Dari hasil penelitian yang telah dijabarkan di atas, dapat diketahui bahwa orang Jepang mempunyai cara untuk menggungkapkan kesedihan yang amat mendalam yang disebut dengan Mono no Aware. Orang Jepang ketika menyampaikan perasaan sedih yang amat mendalam memiliki cara meraka berbeda dari orang Asia lainya khususnya orang Indonesia seperti contoh berikut orang Jepang ketika memiliki peliharaan yang sangat disayangi dan binatang peliharaan itu pun meninggal, untuk mengenang binatang peliharaan tersebut mereka memilih untuk berkabung sampai rasa sedih mereka atas kehilangan binatang pelihaaranya pun berakhir dan memreka pun membuatkan altar atau tempat penghormatan untuk anjing tersebut itulah gambaran terhadap Mono no Aware. Di sini peneliti menggunakan film utuk memudahkan mencari gambaran tentang Mono no Aware tersebut. Beberapa tahun silam, film hanya dikenal sebagai keajaiban, bagaimana sebuah gambar dapat bergerak, mengeluarkan suara dan terlihat nyata. Film besutan Kazuaki Kiriya asal Jepang. Film ini diangkat berdasarkan kisah legenda kepahlawanan seorang ninja (shinobi) di Jepang yang bernama Ishikawa Goemon. Film ini bercerita tentang situasi Jepang pada tahun 1582 dimana perjuangan sang tokoh utama (Goemon) untuk membalaskan dendam tuannya yaitu Oda Nobunaga serta mengembalikan kepemimpinan Jepang kepada orang yang tepat.

Scene yang menunjukkan ketika Koeita memberikan sedikit makanan kepada ibunya yang sedang sakit, pada saat dia sendiri dalam kondisi yang sangat lapar. Rasa laparnya dikalahkan oleh kesedihannya karena melihat ibunya yang sudah begitu lama menderita sakit dalam perjuangan Koeita membeli semangkok bubur untuk ibunya yang tercinta dia rela mencuri dan membahayakan nyawanya bahkan bubur tersebut bukan terbuat dari beras namun terbuat dari lobak yang dimasak seperti bubur. Koeita berusaha keras mencari makanan dengan cara mencuri dan memungut apa saja yang ditemukan yang bisa dijadikan sebagai makanan. Suatu hari, Koeita berhasil mencuri sedikit uang. Namun, uang yang didapatkan dari hasil mencuri hanya cukup untuk membeli 1 (satu) mangkok bubur. Betapa menyedihkanya seorang anak kecil yang berjuang untuk kelangsungan hidupnya dan juga hidup ibunya ia rela di kejar-kejar orang karena mencuri, rela juga di pukul sampai berdarah hanya untuk mendapatkan 
makanan dan kehidupan yang layak. Inilah tanda dari sisi Mono no Aware yang begitu indah dalam menggungkapkan seni ekspresi kesedihan dari orang lain.

Chacha Sama adalah seorang putri yang kaya raya ditandai dengan pakaian serba mewah dan istana yang sangat megah dan indah. Namun dibalik keberlimpahan harta benda, Chacha Sama terlihat sangat sedih ketika akan dijadikan selir oleh Toyotomi Hideyoshi. Ketika Chacha Sama yang sedang jatuh cinta dengan Goemon, cinta yang dipendam Chacha Sama kepada Goemon telah dirasakan sejak dulu, sejak Goemon menyelamatkan Chacha Sama dari pembunuh bayaran. Cinta tersebut adalah cinta pandangan pertama yang dirasakan oleh Chacha Sama ketika itu pembunuh bayaran sedang mengincar Chacha Sama dan dilihat oleh Goemon. Aksi penyelamatan yang dilakukan oleh Goemon membuat Chacha Sama jatuh cinta kepadanya dan setiap hari Chacha Sama memikirkan dan membayangkan wajah Goemon. Pada saat Chacha sama mendengar bahwa dia akan di persunting, hati Chacha Sama merasa hancur dan sangat bersedih karena dia mencintai Goemon. Untuk menghibur dirinya dia pergi ke suatu taman ditemani oleh pelayannya. Di sana Chacha Sama menceritakan isi hatinya tentang perasaanya kepada Goemon dan pelannya berusaha untuk menghiburnya. Dalam scene ini digambarkan kesedihan seseorang yang dikarenakan akan menikah dengan orang yang tidak dicintainya. Limpahan harta, kemegahan istana, tidak mampu memberikan kebahagiaan pada Chacha Sama ketika dipersunting oleh Toyotomi Hideyoshi. Hal ini dikarenakan tidak adanya rasa cinta yang mendasari hubungan mereka. Perasaan Chacha Sama tersebut terlihat dari ekspresi wajahnya yang mengkerut kebawah dan juga matanya yang terlihat seperti sedang menahan air mata.

Goemon berusaha menyelamatkan temannya Zaizou dari hukuman mati yang diberikan oleh Toyotomi Hideyoshi tetapi usahanya sia-sia. Dalam usaha menyelamatkan Zaizou, Goemon menerobos kerumunan ratusan warga dengan sekuat tenaga padahal kondisi Goemon saat itu sedang terluka. Sayangnya, sesampainya Goemon disana, Zaizou sudah diberi hukuman mati tepat di depan mata Goemon. Goemon hanya bisa terdiam memandang kearah Zaizou yang sudah dihukum mati orang-orang disekitar Goemon pun ikut terdiam tampa kata menyaksikan kejadian tersebut. Suasana pada kejadian tersebut sangat mendukung karena terjadi ketika langit sedang mendung dan juga hembusan angin yang kencang menambah suasana kesedihan menyelimuti kejadian tersebut. Kesedihan yang dirasakan Goemon sangat mendalam karena Zaizou merupakan satu-satunya teman pada masa kecilnya yang tumbuh dan berlatih menjadi ninja (shinobi) bersama Goemon. Tatapan mata Goemon kosong dia tidak bisa berpikir dan berbuat apa-apa lagi Goemon hanya bisa menghampiri dengan pelan-pelan mayat Zaizou sambil tetap memandangnya.

Sisi yang menampilkan Mono no Aware dalam tanda visual pada film Goemon adalah usaha Goemon yang berjuang menyelamatkan Zaizou dari hukuman mati yang diberikan oleh Toyotomi Hideyoshi yang ditandai dengan ekspresi wajah Goemon yang seakan tidak percaya melihat kematian temannya di depan matanya sendiri. Dengan wajah mengkerut keatas dan mulut menganga, mata melotot merupakan pertanda ekspresi kesedihan yang mendalam pada dirinya. Ditambah dengan ekspresi wajah orang-orang yang disekitar Goemon yang ikut sedih melihat kejadian tersebut semua orang memandang dengan mata yang melotot, bibir yang terbuka seakan tidak percaya dengan kejadian yang ada dihadapan mata mereka. Ditambah dengan suasana yang mendung disertai angin yang berhembus kencang. Penambahan musik dan pencahayaan juga menambah kesedihan yang ada di scene tersebut.

Disaat Zaizou tertangkap dan akan dihukum mati, tetapi mengaku sebagai Goemon agar Goemon tidak lagi dikejar oleh Toyotomi Hideyoshi. Zaizou sudah tahu dia akan dihukum mati tetapi dia masih bisa tersenyum. Dalam kejadian itu tampak suasana sangat menyedihkan dimana terlihat Zaizou yang sedang diikat di sebuah tiang yang besar dengan seorang algojo berdiri yang siap untuk mengeksekusi Zaizou.

Dari penggambaran tersebut bisa dilihat sebuah tiang yang menggambarkan kekuatan yang bisa digunakan sebagai penopang dan penghancur. Algojo mengambarkan seseorang yang datang membawa ketakutan menghantui orang-orang 
dari setiap sudut dengan perawakan yang besar menggunakan baju berwarna hitam memakai topeng dan sebuah pedang besar digengamanya siap memberikan rasa takut terhadap orang yang memandanya. Rasa takut yang seperti ini yang dirasakan oleh Zaizou ketika akan dieksekusi di hadapan banyak orang dan wajahnya penuh dengan penyesalan tetapi juga senang karena dia akan segera menyusul istri dan anaknya. Sisi yang menampilkan Mono no Aware dalam tanda-tanda pada film Goemon adalah usaha Zaizou untuk menyelamatkan Goemon agar tidak tertangkap oleh Toyotomi Hideyoshi dengan cara mengaku sebagai Goemon dan menerima hukuman mati. Ditandai oleh raut wajah Zaizou yang sedih dengan senyum yang menggambarkan keiklasan seorang teman dalam mengorbankan nyawanya untuk menggantikan penderitaan temannya. Disertai juga dengan musik yang membuat suasana mencekam dan menyedihkan juga ditambah efek pencahayaan yang sangat mendukung suasana esekusi tersebut. Dalam film ini tertuang pesan-pesan moral yang ingin disampaikan oleh sang sutradara. Di awal scene saja, penonton sudah disuguhi berbagai macam tanda-tanda Mono no Aware melalui sebuah tampilan visual. Tentang perjuangan Goemon dan ketragisan Zaizou untuk mengembalikan kepemimpinan Jepang kepada orang yang tepat. Saat Goemon memandangi bekas eksekusi dari Zaizou dengan raut wajah yang tampak tidak percaya bahwa Zaizou telah tiada, ekspresi tersebut menyampaikan pesan duka yang mendalam yang tidak bisa terungkapkan dengan kata-kata. Dalam kejadian ini terlihat Goemon yang tertunduk meratapi penyesalan dan kesedihanya telah kehilangan sahabatnya.

Wajah Goemon menggambarkan kesedihan yang tidak bisa diungkapkan dengan kata-kata matanya melotot kebawah tampa berkedip sedikit pun dan bibirnya menutup erat tanda kesedihan yang meliputi sampai tidak percaya akan apa yang terjadi. Ditambah juga dengan ekspresi wajah orang yang berdiri dibelakang Goemon dengan ekspresi wajah memandang kearah Goemon. Wajahnya juga terlihat sedih terdiam Cuma bisa memandangi Goemon saja, hal ini terlihat dari sorot mata dan ekspresi wajahnya yang terfokus kearah Goemon dan gayanya berdiri tegap mengepalkan tangan menambah kesan ikut tidak percaya dan sedih atas kejadian yang terjadi saat itu. Kejadian ini sangat menggambarkan sisi Mono no Aware dalam tanda visual pada film Goemon dengan ditandai oleh kesedihan mendalam Goemon akan kematian temannya. Dengan menunjukkan raut muka yang seakan tidak percaya terhadap apa yang telah terjadi, seperti mata melotot, mata berkaca-kaca menahan air mata, mulut yang menutup seakan tidak bisa mengeluarkan kata-kata, ditambah lagi dengan efek musik dan pencahayaan yang mendukung, membuat kejadian tersebut terlihat begitu mengerikan.

Ditandai dengan beberapa tanda-tanda Mono no Aware yang memberikan kesan bahwa film ini sangat banyak mengandung kejadian-kejadian yang menyedihkan. Berdasarkan pemaparan di atas, bahwa dalam film Goemon terdapat banyak pesanpesan moral yang disampaikan. Salah satunya tentang perjuangan untuk mengembalikan kepemimpinan Jepang kepada orang yang tepat. Banyak terdapat scene yang mencerminkan Mono no Aware dengan menggunakan teknik Mise en Scene sebagai teori pendukung yang membuat setiap adegan menjadi lebih bagus seperti visual pada film, efek suara, musik dan efek zoom yang di gunakan saat pengambilan gambar film.

\section{Kesimpulan dan Saran}

Berdasarkan hasil penelitian yang dilakukan mengenai Mono No Aware pada film Goemon dengan menggunakan teknik mise en scene dapat ditarik kesimpulan sebagai berikut.

Mono No Aware terlihat pada saat tokoh Koheita yang ada dalam film ini digambarkan sebagai seorang anak kecil yang menjadi korban kekejaman penguasa saat itu. Dengan setting film tersebut mengalami benturan-benturan kekejaman antara kenyataan dan harapan untuk hidup layak bersama sang ibu. Namun, kenyataannya, ia dan sang ibu menghabiskan hidupnya dengan penderitaan. Dengan tatanan ruang yang menceritakan 
sebuah adegan di dalam gubuk kecil yang ditata sedemikian rupa sehingga tercipta sebuah ruang menggambarkan ketidak layakan untuk dihuni. Di tambah dengan makeup dan kostum membuat aktor terlihat seperti betul telah mengalami sebuah kekerasan. Akting sangat berpengaruh dalam mengetahui Mono No Aware dalam sebuah film, dengan didukung oleh kemampuan akting memudahkan untuk mengetahui apa yang di maksud dan dialami oleh tokoh di sebuah film. Dan pencahayaan yang berperan memberikan efek atau waktu kejadian di film tersebut.

Setelah mengulas pesan dalam film Goemon, peneliti dapat memberikan beberapa saran yang dapat dijadikan sebagai acuan bagi pembaca maupun peneliti lain yang akan melakukan penelitian serupa.

Film Goemon sangat baik digunakan sebagai bahan untuk melakukan penelitian terhadap bentuk seni sastra Mono No Aware di Jepang, dan baik untuk meneliti gambaran Mono no Aware. Karena keterbatasan waktu, penelitian ini dilakukan berdasarkan data-data visual saja. Namun akan sangat baik apabila dalam penelitian serupa dengan menggunakan film Goemon selanjutnya selain menggunakan data-data visual, juga menggunakan data-data verbal. Dalam melakukan penelitian rasa iba (Aware) di Jepang, diharapkan bagi calon peneliti untuk mempelajari rasa iba (Aware) pada setiap pembagian zaman di Jepang baik modern maupun tradisional, dan juga ilmu sejarah (Historis) yang mendukung. Karena semua itu memiliki keterkaitan yang dapat mendukung penelitian yang dilakukan.

\section{Daftar Pustaka}

Aso, Isoji, dkk. 1980. Nihon Bungaku Gairon. Tokyo: Shuei Shuppan.

Denesi, Marcel. 2004, Massages, Sign and Meaning: A Basic Texbook in Semiotics and Comunikation Theory.

Jesika, Ismail. (2020). "Memahami Apa Itu Mise en Scene dalam Produksi Film". (online, https://studioantelope.com/apa-itu-mise-en-scene/, diakses tanggal 20 Agustus 2020).

Jonathan, Sarwono. 2006. Metode Penelitian Kualitatif dan Kuantitatif. Yogyakarta: Graha IImu

Kodansha. 1994. Japan, An Illustrated Encyclopedia 2. Tokyo: Kodansha Ltd.

Lustyantie, Ninuk. (2012). " Pendekatan Semiotika Model Roland Barthes dalam karya sastra Prancis”.

Mente, Boye De. (2006). "Elements of Japanese Design. North Clarendon". Tuttle Publishing.

Marra, F. Michael. (2007). The Poetics of Motoori Norinaga. Dalam "A Hermeneutical Journey". USA: University Of Hawai'l Press.

Marra, Michael.(1999)." Modern Japanesse Aesthetics: A Reader". USA: University Of Hawai'l Press.

Pratista, Himawan. (2008). "Memahami Film”. Yogyakarta:Homerian Pustaka.

Perkins, Dorothy. (1991)."Encyclopedia of Japan: Japanese History and Culture, from Abacus to Zori". New York: Facts on File. 
JPBJ, Vol. 7 No. 1, Februari 2021

ISSN: 2613-9618

Picken, Stuart D.B. (2004). "Source Book in Shinto: Selected Document". USA:

Greenwood Publishing Group.

Sartini, Arianto, Saring. (2010). Jepang 'Habis gelap terbitlah terang': Tinjauan sejarah Jepang pasca perang dunia II. Jurnal Sosio e-Kons, Vol.2 - No.1. 